\section{A scheme for demonstrating some classical genetic principles in the classroom}

\author{
G. A. MarX
}

CERTAIN groups of genes of the garden pea A (Pisum sativum L.) are especially useful for demonstrating a number of classical genetic principles in the classroom. Two such groups will be described.

Segregation, dominance, incomplete dominance, linkage and gene interaction can be illustrated simultaneously by a cross between plants differing for only five genes. Three of these genes, afila $(a f)$, reduced stipules $(s t)$, and acacia $(t l)$, modify leaf morphology $y^{1-3,12,13}$. Triply heterozygous $F_{1}$ plants produce an $F_{2}$ with eight phenotypic classes that can be identified unambiguously in the seedling stage, three weeks after planting. The morphological configurations are themselves unusual and interesting (Figure 1). These three seedling genes reside in separate chromosomes but $a f$ and $t l$ are each linked with a different seed gene, $i$ and $r$, respectively $y^{2,4,6,10-13}$. The $I-i$ locus determines yellow vs. green cotyledon color and it is situated about 15 units from $a f$. $R-r$ conditions smooth (round) vs. wrinkled seed and it lies about 5 units from $t l$. Since the results of segregation for $I-i$ and $R-r$ are already evident in the seed produced by $F_{1}$ plants, the $F_{2}$ seed can be classified and separated prior to planting into four groups: $I /-R /-, I /-r / r, i / i R /-$, and $i / i r / r$. The seedlings derived from these groups are expected, except for the crossovers (or misclassifications!), to display phenotypic differences in leaf morphology in accordance with the linkages specified.

Since $T l$ displays incomplete dominance, heterozygous plants $(T l / t l)$ can be visually distinguished from either of the homozygotes; the tendrils of the heterozygotes are strap-like (Figure 2). Moreover, the combination aflaf $t / / t l$ produces a curious phenotype (Figure 1) that graphically illustrates the principle of gene interaction.

The author is professor in the Department of Seed and Vegetable Sciences, New York State Agricultural Experiment Station, Cornell University, Geneva, New York, 14456.

Table I. The phenotypic consequences of segregation of alleles at three wax-conditioning loci

\begin{tabular}{|c|c|c|c|c|c|c|}
\hline \multicolumn{3}{|c|}{ Genotypes } & \multicolumn{4}{|c|}{$F_{2}$ ratio of phenotypes } \\
\hline Wlo & $W_{s n}$ & Wel & Norma & Partially & Completely & Total \\
\hline+ & + & + & 27 & . & & \\
\hline+ & + & wel & & & 9 & \\
\hline+ & wsp & + & & 9 & & \\
\hline+ & $w s p$ & wel & & & 3 & \\
\hline wlo & + & + & & 9 & & \\
\hline wlo & + & wel & & & 3 & \\
\hline wlo & $w s p$ & + & & & 3 & \\
\hline \multirow[t]{2}{*}{ wlo } & $w s p$ & wel & & & 1 & \\
\hline & & Exp. & 27 & 18 & 19 & 64 \\
\hline
\end{tabular}

The Journal of Heredity 65:252-254. 1974.

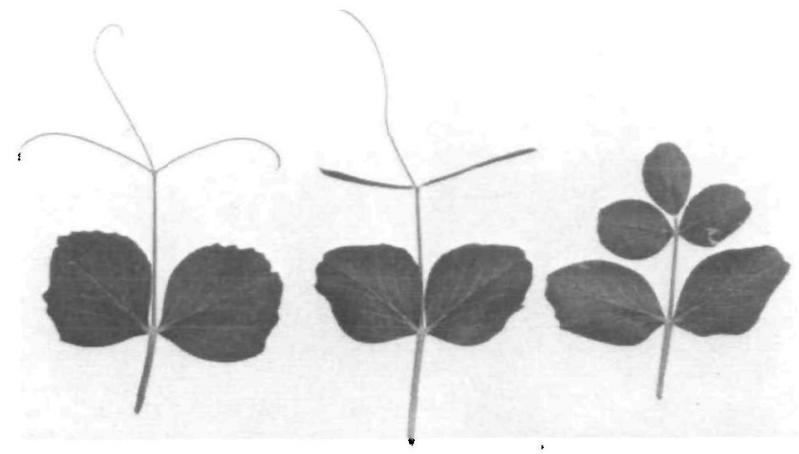

FIGURE 2-Portions of leaves from pea plants that are (l-r): $T l / T l, T l / t l, t l / t l$. The heterozygote shows incomplete dominance, i.e., strap-like tendrils.

Only slightly less useful for demonstration purposes is a group of seedling markers showing gene specificity, additivity, epistasis, linkage, and modified ratios. Three of these, wlo, wsp, and wel, are among a number of Pisum mutants that determine the amount and distribution of wax (bloom). A fourth gene, st, already mentioned, is linked with wel. The action of wlo and wsp is highly specific ${ }^{5,9}$. In wlo/wlo plants there is little or no wax formed on the upper surface of the leaflets, but the lower surfaces and all other plant parts are normal waxy. In wsp/wsp plants, however, only the upper surface of the leaflets, is waxy, and all other plant parts are waxless. When combined in the same plant these two unlinked genes show an additive effect: wlo/wlo wsp/wsp plants are completely waxless.

A recessive mutant wel by itself produces completely waxless plants, so the phenotype produced by wel/wel alone is indistinguishable from the phenotype produced by wlo and wsp together ${ }^{7}$. Selfed $F_{1}$ plants heterozygous at all three loci produce an uncommon $F_{2}$ segregation ratio, viz. $27: 18: 19$ for normal, partially waxless (either $w l o$ or $w s p$ ), and completely waxless plants, respectively (Table I). Since wel/wel precludes wax formation on all plant parts, this gene is epistatic to wlo and wsp.

Pea seedlings can be grown with minimal effort, space, and equipment. Ordinary greenhouse flats containing sand, soil, or some other suitable medium will accommodate 50 to 75 seedlings. The instructor would need only to plant the seeds* and await the results. The

* Seed for the $a$ f st $t$ l system is already available from at least one commercial source. Persons or firms qualified and equipped to produce seed for sale can obtain a very limited number of parental stock seeds from the author. For the first group described, the appropriate parental lines for crossing are: $I-A f$, $S t, R-R l \times i-a f, s t, r-t l$. This coupling phase cross will increase the chances of detecting crossovers in the $I-A f$, and $R-T I$ linkages in populations ranging from $100-200 \mathrm{~F}_{2}$ plants. For the second group the appropriate cross is: Wlo, Wsp, wel-st $\times$ wlo, wsp, Wel-St.

The dealer would make the crosses, plant the $F_{1}$ seed and collect the $F_{2}$ seeds from the $F_{1}$ plants for sale. This aspect requires skill, knowledge of the plant, and proper facilities. In the event of interest, still other groups of genes in peas could be cited for use in this connection. 
seedings can be grown at room temperature but they should receive sufficient light and moisture.

Finally, the presence of peas in the classroom might add a modicum of historical perspective. After all, peas were conspicuously present when all the excitement began, in that quiet monastery garden near Brno.

\section{Summary}

Two different groups of mutants of the garden pea are described for use in classroom instruction to demonstrate a number of classical genetic principles. Besides offering the advantage of living material, the scheme is convenient, inexpensive, and effective in demonstrating a number of phenomena simultaneously in the seedling stage of development.

\section{Literature Cited}

1. Goldenberg, Jose G. "Afila", a new mutation in peas (Pisum sativum L.) Boletin Genetico 1:27-31. 1965.

2. KhangiLdin, V.V. A new gene leaf inducing the absence of leaflets in peas. Interaction between genes leaf and $T l^{w}$. Genetika (Moskva) 6:88-96. 1966.

\section{Milledgeville mongoloid: A rare karyotype of Down's syndrome}

\author{
Donnell Jernigan, Nell Curl, and Clyde \\ KEELER
}

\begin{abstract}
$\prod$ HE HERE are three well-known types of cytologically distinguishable mongolism, all of which are due to the triploid presence of a considerable number of genes on chromosome 21 , especially on the long arm. The most common type of mongolism (referred to here as type 1) is that which displays three independent copies of chromosome $21^{12}$ (see Figure 1). Less common, in our experience, are the cases of three chromosomes 21 in which two are united (G-G Robertsonian translocation) (type 2$)^{9}$. Least common are the cases in which one of the three chromosomes 21 is united with a chromosome 14 (D-G reciprocal translocation) (type 3$)^{8}$.

Type 1 is believed to be due to a lagging chromosome 21 , often during meiosis, so that two chromosomes 21 are included in a maturing egg cell; since this occurs most frequently in women over 35 years of age, this type usually arises de novo. Types 2 and 3 also are thought to be due to inclusion of two chromosomes in a maturing ovum, but in these types mongolism becomes hereditary ${ }^{3}$; this is due to the translocation phenomenon determining that: 1) most of the gene string of two of the three 21's will attach together,
\end{abstract}

The authors are laboratory scientist II, laboratory technician III, and geneticist, respectively, Central State Hospital, Milledgeville, Georgia 31061.
3. Kujala, V. Felderbse, bei welcher die ganz Blattspreite in Ranken ungewandelt ist. Archivum Societatis Zoologicae Botanical Fennicae "Vanamo" 8:44-45. 1953.

4. Lamprecht, H. Genstudien an Pisum sativum. IV. Uber Vererbung von Wachslosigkeit und ein neues Gen fur lokale Ausbildung von Wachs, Wsp. Hereditas 25:459-471. 1939.

5. - Die Genekarte von Pisum bei normaler Struktur der Chromosomen. Agri. Hortique Genetica 19:360-401. 1961.

6. Marx, G.A. Linkage relations of Af. Pisum Newsletter 1:9-10. 1969.

7. Pisum Newsletter 1:10-11. 1969.

8. - New linkage relations for chromosome III of Pisum. Pisum Newsletter 3:18-19. 1971.

9. Nilsson, E. Erblichkeitsversuche mit Pisum. VIII. Ein Lokalisationsgen fur Wach und sein Verhalten zu den Genen $W a$ und $W b$. Hereditas 17:216-222. 1933.

10. SNOAD, B. Linkage between $A f$ and $l$ on chromosome I. Pisum Newsletter 3:43. 1971.

11. Vilmorin, Ph. de and W. Bateson. A case of gametic coupling in Pisum. Proc. Roy. Soc. Lond. B 84:9-11. 1912.

12. Wellensiek, S.J. Genetic monograph on Pisum. Biblio. Genet. 2:343-476. 1925.

13. White, O. Studies of inheritance in Pisum. II. The present state of knowledge of heredity and variation in peas. Proc. Am. Phil. Soc. 56:487-588. 1917. or 2) one of the three 21's will attach to one of the chromosome 14 pair.

Theoretically, 100 percent of the body cells of all three types of patients may bear their cytogenetic anomaly. On the other hand, mongoloids may be mosaics of karyotypically mongoloid and normal cell lines due to mitotic nondisjunction ${ }^{13}$, or conceivably to the loss of one chromosome 21 from a triploid 21 cell during embryology by nondisjunction; thus, the percentage of mongoloid cells may vary in different tissues of the body.

In this paper, we will describe another cytogenetically distinguishable type of mongolism (that theoretically may become hereditary) involving translocation. The translocation was found in all of several hundred chromosome spreads that we have observed on the patient displaying this type of mongolism.

\section{Case Report}

J.S. (147 138) is an 11-year-old white male, who is $251 / 2$ inches tall and weighs 25 pounds. His body is emaciated and extremely floppy. He has a grade II/VI systolic murmur on the lower left sternal border. He is a restless, nonambulatory, nonverbal patient with flaccid diplegia and profound mental retardation. He cannot dress or feed himself and is not toilet trained. His chromosome count is 46 and his karyotype shows a unique type of translocation. His blood chemistries are normal. His parents attended school up to the eighth grade.

The patient has a typically brachycephalic head, mongoloid features with somewhat low nose bridge and slightly cupped ears, and slightly slanted eyes. He has a fairly large mouth that he often keeps open and a large, furrowed tongue that lacks the central fissure 